\title{
Increased Endogenous PKG I Activity Attenuates EGF-Induced Proliferation and Migration of Epithelial Ovarian Cancer Via the MAPK/ERK Pathway
}

\section{Ting Lan}

Xuzhou Medical University

\section{Ying Li}

Affiliated Hospital of Xuzhou Medical University

Yue Wang

Xuzhou Medical University

Zhongcheng Wang

Xuzhou Medical University

Chunyan Mu

Xuzhou Medical University

Aibin Tao

The Affiliated People's Hospital of Jiangsu University

Jianli Gong

NYU Langone Health

\section{Yuan Zhou}

Xuzhou Medical University

Hao Xu

Hubei Polytechnic University

Shibao Li

Xuzhou Medical University

Bing Gu

Xuzhou Medical University

\section{Ping Ma}

Xuzhou Medical University

Lan Luo ( $\sim$ luolan@xzhmu.edu.cn )

Xuzhou Medical University

\section{Research Article}


Keywords: Epithelial ovarian cancer, PKG I, EGFR, MEK/ERK pathway, metastasis.

Posted Date: March 2nd, 2022

DOI: https://doi.org/10.21203/rs.3.rs-1398745/v1

License: (c) (1) This work is licensed under a Creative Commons Attribution 4.0 International License. Read Full License 


\section{Abstract \\ Background}

The type I cGMP-dependent protein kinase (PKG I) is recognized as a tumor suppressor, but its role in EGFR regulated epithelial ovarian cancer (EOC) progression remains unclear.

\section{Methods}

We evaluated the in vivo and in vitro effects of activated PKG I in EGF-induced EOC cell proliferation, migration, and invasion.

\section{Results}

The expressions of EGFR and PKG I were elevated, but the activated PKG I was decreased in EOC tissues of patients and cells lines. The addition of 8-Br-cGMP, a specific PKG I activator, attenuated the EGFinduced EOC cell proliferation, migration, and invasion in vitro. Similarly, activated PKG I also attenuated EOC progression in vivo using an EOC xenograft nude mouse model. The activated PKG I interacted with EGFR, causing increased threonine (693) phosphorylation and decreased tyrosine (1068) phosphorylation of EGFR, which resulted in disrupted EGFR-SOS1-Grb2 combination. Subsequently, the cytoplasmic phosphorylation of downstream proteins (c-Raf, MEK1/2, and ERK1/2) were declined, impeding the phosphorylated ERK1/2's nucleus translocation, and this reduction of phosphorylated tyrosine (1068) EGFR and ERK1/2 were also abolished by Rp-8-Br-cGMPS.

\section{Conclusions}

Our results suggest that the activation of PKG I attenuates EGF-induced EOC progression, and the 8-BrcGMP-PKG I-EGFR/MEK/ERK axis might be a potential target for EOC therapy.

\section{Introduction}

In 2018, there were an estimated 295,414 new cases and 184,799 deaths from ovarian cancer globally, ranking the 8th most common cancer and cause of death for females [1]. Ovarian cancer is classified by the cells of origin as epithelial (90\%), stromal (5-6\%), and germ cell tumors (2-3\%) [2]. The most common type of epithelial ovarian cancer (EOC) usually presents with no specific symptoms, making it mostly diagnosed at late-stage with a low 5-year survival rate of $29 \%[3,4]$. In contrast, few early-staged patients $(15 \%)$ have a markedly high rate of $92 \%$, implying the need to understand EOC's etiology. EOC comprises heterogeneous histological subtypes with unique molecular features. Mutations in breast cancer susceptibility genes BRCA1/2 and other genes like CDH1, PALB2, PTEN, and TP53 have been identified as causative factors in hereditary EOC $[5,6]$. The poly (ADP-ribose) polymerase (PARP) 
mediates DNA repair in BRCA1/2-mutated cells facilitating its survival [7]. Thus, PARP inhibitors have been tested clinically achieving therapeutic benefits, especially for BRCA-mutated EOC. But inconsistent results are yielded in patients without $B R C A$ mutation [8]. Apart from the PARP inhibitors, antiangiogenesis agents have also generated positive outcomes in randomized phase III trials, associated toxicity and adverse events are reported yet [9]. Therefore, novel therapy target discovery is imperative to improve EOC outcome and mortality.

Epidermal growth factor receptor (EGFR) is a transmembrane glycoprotein and a member of the cell membrane receptor tyrosine kinase family [10]. EGFR binds with its cognate ligands (EGF, etc.), promoting carcinogenesis via cell proliferation, migration, and invasion [11]. EGFR is overexpressed in all histological EOC subtypes, ranging from 9-62\% varied with the antibody and cutoff value [12-14]. Overexpressed EGFR is associated with the late-stage and high patient mortality in EOC $[15,14]$. Nevertheless, discouraging results have been reported in clinical trials using EGFR-targeted agents [16]. And EGFR seems to have a less role in prognostic evaluation of EOC $[12,17]$. For this reason, it warrants profound insights into identifying the mechanisms of resistance to anti-EGFR therapies and the role of EGFR in EOC.

cGMP-dependent protein kinase $\mathrm{G}(\mathrm{PKG})$ is a serine/threonine kinase widely expressed in mammalian cells and contains two major types that soluble PKG I and membrane-associated PKG II. Upon binding to cGMP, PKG I is activated and phosphorylates targeted proteins at serine/threonine residues regulating downstream effects. The activation of PKG I is involved intestinal secretion, bone growth, neuronal signaling, and cell apoptosis $[18,19,14]$. Recently, emerging studies have suggested an anti-tumor effect of activated cGMP/PKG signaling in multiple cancer types via inhibiting cell growth, metastasis, and immunity [20]. Thus, the cGMP/PKG pathway may serve as a potential target for cancer treatment. Traci $R$ et al. found that SGC stimulators and PDE5 inhibitors increased cGMP levels, reducing cell viability and apoptosis in head and neck squamous cell carcinoma[21]. Fallahian F et al. reported that the PKG I was sufficient to induce apoptosis in estrogen receptor-positive and negative breast cancer cell line[22]. The function of PKG I in ovarian cancer is controversial. Some research reported PKG la activity significantly induced DNA synthesis and cell proliferation $[23,24]$. While others indicated that PKG I inhibited cell proliferation in ovarian cancer [25]. Notably, the role of PKG I in EGFR-related EOC progression remains unclear.

In the present study, we first examined the expressions of PKG I and EGFR in EOC tissues and cells. Then we tested whether the 8-Br-cGMP, PKG I activator, could affect the EGF-induced EOC cell growth and metastasis in vivo and in vitro. Last, we investigated the underlying mechanisms of activated PKG I in attenuating EGF-induced EOC progression.

\section{Materials And Methods}

\section{Cell Lines, Antibodies, And Reagents}


Human EOC cell lines SKOV3 and A2780, and the human normal epithelial cell line IOSE80 were freshly obtained from American Type Culture Collection (ATCC) with authentication by short-tandem-repeat analyses. The cells were cultured in Dulbecco's Modified Eagle's Medium containing penicillin/streptomycin (DMEM) (Kaiji, Jiangsu, China) with 10\% fetal bovine serum (Gibco, Grand Island, $\mathrm{NY}, \mathrm{USA}$ ) in an atmosphere containing $5 \% \mathrm{CO}_{2}$ at $37^{\circ} \mathrm{C}$.

Antibodies against PKG I, EGFR, p-EGFR(T693), ERK1/2, VASP, c-Raf, MEK1/2, p-VASP (Ser 239), p-c-Raf (Ser338), and MEK1/2 (Ser217/Ser221) were purchased from Affinity Biosciences (Affinity Biosciences, $\mathrm{OH}, \mathrm{USA}$ ). Antibodies against Grb2 and p-EGFR (Tyr1068) were purchased from Cell Signaling Technology (Danvers, MA, USA). Antibodies against Sos1 and p-Erk1/2 (Thr202/Tyr204) were purchased from Santa Cruz (Santa Cruz, CA, USA). The antibody against $\beta$-actin was purchased from Proteintech (Proteintech, Chicago, USA).

EGF was purchased from PeproTech (Rocky Hill, NJ, USA), 8-Br-cGMP, and Rp-8-Br-cGMPS were purchased from Biolog Biotechnology (Bremen, Germany). The incubation time of EGF was 5 minutes.

\section{Western Blot}

\section{Western blot}

Cells were collected and lysed in cell lysis buffer (Kaiji, Jiangsu, China) on ice for 30 min. Subsequently, the supernatant was separated by centrifugation at $14000 \mathrm{~g}, 4^{\circ} \mathrm{C}, 20 \mathrm{~min}$. The protein concentrations were determined with a BCA kit (Kaiji, Jiangsu, China), and protein samples were mixed with $5 \times$ sodium dodecyl sulfate (SDS) loading buffer (Beyotime, Beijing, China) before denaturation in the boiling water bath for $10 \mathrm{~min}$. Proteins were separated via $8-12 \%$ sodium dodecyl sulfate polyacrylamide gel electrophoresis (SDS-PAGE) and then transferred to polyvinylidene difluoride (PVDF) membranes (Millipore, Bedford, MA, USA). Next, the membranes were blocked with $5 \%$ skimmed milk for $2 \mathrm{~h}$ at room temperature and then incubated with primary antibodies overnight at $4^{\circ} \mathrm{C}$. The following day, the membranes were incubated with horseradish peroxidase-conjugated secondary antibody for $1 \mathrm{~h}$ at room temperature. All bands were detected using the electrochemiluminescence kit and scanned by Bio-Rad (Hercules, CA, USA). $\beta$-actin served as an internal control. Image Lab software (4.0) was used for the quantitative analysis of the gray values.

\section{Cell Counting Kit-8 (Cck-8)}

Approximately $4 \times 10^{3}$ cells were seeded in 96 -well plates in DMEM containing $10 \% \mathrm{FBS}$, penicillin/streptomycin. After the indicated treatment, $100 \mu \mathrm{L}$ free medium containing $10 \mu \mathrm{L}$ CCK-8 solution (vicmed, Jiangsu, China) was added to each well and incubated for $1 \mathrm{~h}\left(37^{\circ} \mathrm{C}, 5 \% \mathrm{CO}_{2}\right)$. The optical density values were detected at $450 \mathrm{~nm}$ using an enzyme labeling instrument. 


\section{Colony Formation}

Approximately 500 cells were plated on 6-well plates in DMEM containing 10\% FBS, penicillin/streptomycin. About $10 \sim 14$ days later, visible colonies were fixed by $4 \%$ paraformaldehyde for $15 \mathrm{~min}$ and then stained with $0.1 \%$ crystal violet for $15 \mathrm{~min}$. The units of colony formation were counted using Image J software (1.52v).

\section{Wound Healing Assay}

Approximately $5 \times 10^{6}$ cells were seeded in 6-well plates in DMEM containing $10 \%$ FBS penicillin/streptomycin. Next day, a $10 \mu \mathrm{L}$ tip was used to scratch the cells in the plates. And the cells were washed three times with PBS to remove cell debris. Then cells were treated with serum-free medium and the indicated compounds. Microphotographs were taken at 0,24 , and $48 \mathrm{~h}$ after wounding. The wound area was calculated by manually tracing the cell-free area in the captured images using Image $\mathrm{J}$ software $(1.52 \mathrm{v})$.

\section{Trans-well Migration And Invasion Assay}

For the migration assay, $4 \times 10^{4}$ cells were seeded into the upper chambers of the trans-well plates ( $8 \mu \mathrm{m}$ pore size; Corning, NY, USA) in $200 \mu \mathrm{L}$ serum-free culture medium, whereas $600 \mu \mathrm{L}$ of DMEM medium supplemented with $10 \%$ FBS was added to the lower compartments of the chambers. For the invasion assay, the chambers were coated with a thin layer of Matrigel before the cells were seeded. After 24 or $48 \mathrm{~h}$ of incubation at $37^{\circ} \mathrm{C}$ in a $5 \% \mathrm{CO}_{2}$ incubator, the cells remaining in the upper chamber were removed carefully with cotton swabs. The cells migrated or invaded to the bottom of the chamber were fixed with $4 \%$ paraformaldehyde solution for $15 \mathrm{~min}$ and stained with a $0.1 \%$ crystal violet solution for $10 \mathrm{~min}$. Finally, the stained cells were counted in five randomly selected fields per membrane under an inverted light microscope.

\section{Immunofluorescence And Immunohistochemistry (Ihc)}

Approximately $1 \times 10^{3}$ cells in the 24 -well plates were fixed with $4 \%$ paraformaldehyde at room temperature for $15 \mathrm{~min}$. Then, the cells were permeabilized with $0.3 \%$ Triton-X 100 for $10 \mathrm{~min}$ and incubated with $5 \%$ BSA for $1 \mathrm{~h}$ at room temperature. The cells were incubated with the indicated primary antibodies at $4^{\circ} \mathrm{C}$ overnight and then with the corresponding secondary antibodies avoiding light at room temperature for $1 \mathrm{~h}$ next day. Subsequently, $200 \mu \mathrm{L}$ DAPI (Beyotime, Beijing, China) was applied for $10 \mathrm{~min}$ at room temperature to stain cell nuclei.

Tissues were fixed with $10 \%$ neutral formalin and embedded in paraffin. sections were cut serially from paraffin-embedded tissues, placed in a $60^{\circ} \mathrm{C}$ incubator for $1 \mathrm{~h}$. Antigen retrieval was implemented using 
sodium citrate antigen retrieval solution $(\mathrm{pH6.0})$ through microwave method after dewaxing and rehydration with xylene and gradient ethanol, and endogenous per-oxidase was removed using $3 \% \mathrm{H}_{2} \mathrm{O}_{2}$. After $30 \mathrm{~min}$ of closure of the $3 \% \mathrm{BAS}$, the slices were incubated overnight with the first antibody at $4^{\circ} \mathrm{C}$. On the next day, the sections were washed with PBS to incubate second antibodies for 50 min. Finally, sections were stained by diaminobenzidine tetrahydrochloride (DAB) and hematoxylin staining.

\section{Coimmunoprecipitation (Co-ip) Assay}

The lytic cells were transferred to microcentrifuge tubes and centrifuged at $140,000 \mathrm{~g}$ for $20 \mathrm{~min}$ at $4^{\circ} \mathrm{C}$. The supernatants were transferred to another EP tube and incubated with primary antibodies overnight at $4^{\circ} \mathrm{C}$ with agitation. The second day, the Magnetic beads (MedChemExpress, New Jersey, USA) were added to the EP tube and stirred for 2 hours at $4^{\circ} \mathrm{C}$. Then washed four times and boiled for use in the western blot analysis.

\section{Mass Spectrometry (Ms)}

To identify phosphorylation sites, EGFR was immunoprecipitated from the cellular extract of $\sim 5 \times 10^{7}$ SKOV3 and A2780 cells which were serum-starved for $12 \mathrm{~h}$ and then treated with 8-Br-cGMP ( $250 \mathrm{mM})$ for $1 \mathrm{~h}$. Afterwards, the precipitated samples underwent on-bead enzymatic digestion. The phosphorpeptides of the digestion products were enriched by Tidoped mesoporous silica (Ti-MPS) and then subjected to Nano LC-MS/MS according to reference [14]. The acquired MS raw files were analyzed by MaxQuant environment (version 1.2.2.5). The tandem MS was searched against the UniProt proteome (version 20120418). Enzyme specificity was set to trypsin (KR/P). Carbamidomethyl (C) was chosen for fixed modifications and oxidation on methionine; the phospho $(S, T, Y)$ was set as variable modifications. The false detection rates for peptides, proteins, and phosphorylation were all set below 0.01 . All the other parameters in MaxQuant were set to default values.

\section{Xenograft Experiments}

Four to six-week-old female athymic nude mice were purchased from the Central Laboratory of Animal Science of Xuzhou Medical University, and the animal facility was SPF and was kept at $20 \sim 24^{\circ} \mathrm{C}$. The dark/light cycle was $12 / 12 \mathrm{~h}$, and cages were plastic, with the maximum number of companions being five adults/cage. First, $5 \times 10^{6}$ A2780 cells were injected under the skin of nude mice, and when the tumor grew to about $1 \mathrm{~cm}^{3}$ in size, the nude mice were sacrificed. The subcutaneous tumor was removed and digested with $0.125 \%$ trypsin for 8 to 10 times. Then the supernatant was collected, filtered with a 200 mesh cell filter, and cultured in a petri dish. After 4 to 5 passages, $5 \times 10^{6} \mathrm{~A} 2780$ cells were injected into the abdominal cavity of nude mice. The next day, PBS and 8-Br-cGMP were injected into different groups. After about 2 weeks, all the nude mice were sacrificed, and the liver and tumor were collected for further analysis. 


\section{Statistical analysis}

All the data were analyzed using SPSS 19.0 (SPSS Inc., Chicago, IL, USA) and GraphPad Prism 7.0

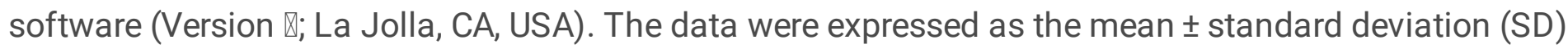

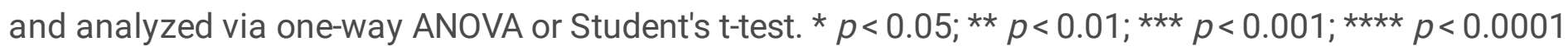
were considered statistically significant.

\section{Results}

\section{The expression of PKG I was elevated, but its activity was downregulated in EOC tissues and cell lines.}

We first confirmed that the EGFR was overexpressed in EOC tissues by IHC analysis (Fig. 1A), consisting with the previous studies [26]. We then investigated the expression of PKG I and its activity by the phosphorylation of Vasodilator Stimulated Phosphoprotein (VASP) at serine 239 [27]. The expression of PKG I was elevated, but the phosphorylation of VASP at serine 239 (p-VASP) was downregulated in EOC tissues (Fig. 1A). Furthermore, we also found elevated EGFR and PKG I expression and declined p-VASP expression in EOC cells (SKOV3 and A2780) than that of normal epithelial cells (IOSE80) (Fig. 1B, C).

\section{Activation of PKG I attenuated EGF-induced EOC cell proliferation, migration, and invasionin vitro.}

Uncontrolled proliferation is a major feature of cancer cells. We first found the 24h-EGF treatment (200 $\mathrm{ng} / \mathrm{ml}$ ) significantly increased the cell viability of SKOV3 and A2780 cells using the CCK-8 assay (Fig. 2A). We also found that the 8-Br-Cgmp (0, 50, 250, $500 \mu \mathrm{M})$ supplement, a specific PKG I activator, upregulated the expression of p-VASP in a dose-dependent manner (supplement Fig. 1A, B). Significantly, EGF-induced EOC cell proliferation was attenuated by the 8-Br-cGMP $(0,50,250,500 \mu \mathrm{M})$ supplement dose-dependently (Fig. 2A). We also assessed whether the 8-Br-cGMP supplement could inhibit EOC cell proliferation continuously. The cell viability of EOC cells was evaluated after treatment with EGF (200 $\mathrm{ng} / \mathrm{ml})$ and 8 -Br-cGMP $(250 \mu \mathrm{M})$ for $0,12,24$, and $48 \mathrm{~h}$. The cell viability of SKOV3 and A2780 cells were significantly decreased at 24 and $48 \mathrm{~h}$ compared with that of Oh culture (Fig. 2B). We then confirmed the effect of activated PKG I on EOC cell proliferation by the clone formation assay (Fig. 2C). The EGF treatment $(200 \mathrm{ng} / \mathrm{ml})$-induced high number and area of clone formation in SKOV3 and A2780 cells were significantly suppressed by the 8-Br-cGMP supplement (500 $\mu \mathrm{M})$ (Fig. 2D).

Next, we examined the effect of activated PKG I on EOC cell migration and invasion. The EGF treatment $(200 \mathrm{ng} / \mathrm{ml})$ significantly increased the cell migration of SKOV3 and A2780 cells using the wound healing (Fig. 3A, B) and trans-well assays (Fig. 3C, D). Similarly, the 8-Br-cGMP supplement markedly suppressed EGF-induced cell migration in SKOV3 and A2780 cells dose-dependently (Fig. 3A, B). And this was further proved by the trans-well assay (Fig. 3C, D). The EGF-induced cell invasion in SKOV3 and A2780 cells were also blocked by the 8-Br-cGMP (500 $\mu \mathrm{M})$ supplement (Fig. 3E, F).

Rp-8-Br-cGMPS, the antagonist of 8-Br-cGMP, was a PKG I inhibitor. So, we investigated whether Rp-8-BrcGMPS could reverse the effect of activated PKG I. The Rp-8-Br-cGMPS treatment ( $250 \mu \mathrm{M})$ indeed 
reduced the elevated p-VASP expression by 8-Br-cGMP supplement in SKOV3 (supplied Fig. 1C) and A2780 cells (supplied Fig. 1D). Consequently, the inhibition effect of activated PKG I on EOC cell proliferation, migration, and invasion were reversed by Rp-8-Br-cGMPS treatment (supplied Fig. 2, 3.). These data suggested that improved PKG I activity could suppress the EGF-induced EOC proliferation, migration, and invasion in vitro.

\section{Activation of PKG I suppressed tumorigenesis and metastasisin vivousing an EOC xenograft model.}

Next, we speculated that activation of PKG I could suppress tumor growth and metastases in vivo using an EOC xenograft mouse model. A2780 cells were intraperitoneally injected into the nude mice, and 8-BrcGMP ( 5 or $20 \mathrm{mg} / \mathrm{kg}$ ) or PBS as control was administered the next day. After three weeks, the average volume (Fig. 4A) and weight (Fig. 4B) of the abdominal tumor were lower in mice injected with 8-Br-cGMP $(20 \mathrm{mg} / \mathrm{kg}$ ) than the control. We also counted the tumor number that metastatic to the liver. The 8-BrcGMP administration inhibited EOC's liver metastasis in a dose-dependent manner (Fig. 4C, D). The control mice exhibited higher EGFR, Ki-67, and MMP-9 expressions compared with that of 8-Br-cGMPtreated mice, resulting in promoted tumorigenesis and metastasis (Fig. 4E). We also examined the ovarian tumor nodules that metastatic to the pleural cavity of mice. The mice with 8-Br-cGMP ( 5 or 20 $\mathrm{mg} / \mathrm{kg}$ ) treatment exhibited a lower number and volume of tumor nodules in the pleural cavity than that of mice with A2780 injection alone (supplied Fig. 4). These data suggested that activated PKG I by the 8Br-cGMP treatment inhibited in vivo metastatic colonization of ovarian cancer.

\section{Activated PKG I bound with EGFR leading its threonine 693 site phosphorylation.}

Then we investigated the mechanisms underlying the tumor-suppressive effects of activated PKG I. The localization of EGFR and PKG I was visualized by confocal laser scanning microscopy. Subcellular localization analysis revealed that EGFR was located both in the cytomembrane and nucleus of EOC cells. PKG I was predominantly located in the cytomembrane and cytoplasm, but less in the nucleus of EOC cells. Overlapping fluorescence signals showed the co-localization of EGFR and PKG I in the cytomembrane but less in the nucleus of EOC cells (Fig. 5A). Furthermore, reciprocal Co-IP assay demonstrated that the PKG I and EGFR were presented in the EOC cells lysates (Fig. 5B). These results suggested that the PKG I bounded to EGFR in the EOC cells. PKG I is a serine and threonine kinase and activated by 8-Br-cGMP. Immunoprecipitation analysis showed that activated PKG I caused serine and threonine phosphorylation of EGFR in SKOV3 and A2780 cells (Fig. 5C). To identify the specific serine and threonine site, MS was performed to analyze the phosphorylation site on EGFR isolated from A2780 cells that treated with EGF $(200 \mathrm{ng} / \mathrm{ml})$ and 8-Br-cGMP $(500 \mu \mathrm{M})$ for $24 \mathrm{~h}$. It identified that T693 was the PKG I specific phosphorylation site on EGFR (Fig. 5D). Western blot analysis further confirmed increased expressions of T693 phosphorylation of EGFR in SKOV3 and A2780 cells treated with EGF $(200 \mathrm{ng} / \mathrm{ml})$ and 8-Br-cGMP $(500 \mu \mathrm{M})$ (Fig. 5E). These results confirmed that T693 of EGFR was the PKG I-specific phosphorylation site.

\section{Activation of PKG I inhibited EGF-induced EGFR/ MAPK/ERK pathway.}


Finally, we investigated the role of activated PKG I in the EGFR related signaling pathway. The addition of EGF increased the expression of the EGFR/MAPK/ERK pathway related proteins including the phosphorylation of EGFR, C-Raf, MEK1/2, and ERK1/2 in SKOV3 (Fig. 6A) and A2780 cells (Fig. 6B). Their elevated expressions were attenuated by the 8-Br-cGMP supplement dose-dependently (Fig. 6A, B). The phosphorylated ERK1/2 would translocate to the nucleus and regulate the phosphorylation and activation of transcription factors inducing proliferation and migration. Indeed, the western blotting and immunofluorescence staining assay revealed that EGF treatment increased the expression of phosphorylated ERK1/2 in the nucleus of SKOV3 (Fig. 6C, E) and A2780 cells (Fig. 6D, F). Whereas, the 8Br-cGMP supplement decreased the expression of nuclear phosphorylated ERK1/2 (Fig. 6C-F). The Co-IP assay revealed that the 8-Br-cGMP-induced EGFR/MAPK/ERK pathway blockade via hampering the EGFinduced EGFR-Grb2-SOS1 binding (Fig. 6G). Importantly, the suppression of phosphorylated EGFR and ERK1/2 induced by the activated PKG I was also abrogated by its inhibitor Rp-8-Br-cGMPS (supplied Fig. 5). Collectively, these results suggested that the activated PKG I attenuated EGF-induced EGFR/MAPK/ERK signaling, leading to suppressed cell growth and metastasis in human EOC (Fig. 7).

\section{Discussion}

In this study, we first observed higher expressions of EGFR and PKG I in EOC tissues and cells, but the level of phosphorylation of VASP was decreased. Then, PKG I activator 8-Br-cGMP, effectively inhibited EGF-induced EOC cell growth and metastasis in vivo and in vitro. Last, we demonstrated that activated PKG I interacted with EGFR and subsequently caused increased threonine 693 site phosphorylation and decreased tyrosine phosphorylation. This led to the decrease of phosphorylated downstream proteins of EGFR, including c-Raf, MEK1/2, and ERK1/2. Consequently, the nucleus translocation of phosphorylated ERK1/2 and related transcription activity was inhibited. This data suggested that elevated PKG I activity attenuated EGF-induced EOC cell proliferation and migration via the MAPK/ERK pathway, serving as a potential target for EOC treatment.

Ovarian cancer, especially EOC, is the most lethal gynecologic malignancy. It is essential to understand the underlying molecular mechanisms involved in the EOC progression to develop novel therapeutic approaches. It has demonstrated that the overexpressed EGFR has been considered as poor prognosis factor of EOC patients. Recently, growing evidence has shown that the CGMP/PKG pathway's activation resulted in the inhibition of cell proliferation and induction of metastasis in cancer cells [28-31, 21, 32]. EGFR is a well-characterized receptor tyrosine kinase and could be activated upon binding with its ligand like EGF. The upregulated tyrosine phosphorylation of EGFR induced an intracellular signal transduction cascade participating biological processes such as cell proliferation, differentiation, migration, adhesion, and angiogenesis [33]. Hence, we investigated whether the activation of the cGMP/PKG pathway also could inhibit EGF-induced EOC cell growth and metastasis. In this study, we first found elevated expression of EGFR in EOC tissues and cell lines, which is in line with the previous findings [26]. Decreased PKG I levels have been confirmed in breast, liver, lung, and colon tumors [31] but its levels in ovarian cancer remained controversial. Wong A.S et al. detected decreased PKG I expression in ovarian cancer cells [34], but we examined increased PKG I expression in EOC tissues and cell lines. Nevertheless, 
the PKG I activity evaluated by the phosphorylation of its substrate VASP were downregulated in EOC tissues and cell lines. Above all, the 8-Br-cGMP supplement, a specific PKG I activator, suppressed the EGF-induced EOC cell proliferation, migration, and invasion in vitro. Activated PKG I also markedly attenuated the growth and metastasis in an EOC xenograft mouse model. Besides, the inhibition effect of activated PKG I in EGF-induced EOC cell growth and metastasis were reversed by the Rp-8-Br-cGMPS treatment, a PKG I inhibitor. Overall, these findings suggested that the inhibition of the cGMP/PKG pathway also functioned in preventing EOC progression.

Last, we elucidated the underlying mechanisms to identify potential EOC therapeutic targets. We demonstrated that the PKG I interacted with EGFR and induced the increased serine and threonine phosphorylation of EGFR. MS analysis found that T693 of EGFR was the PKG I-specific phosphorylation site which is the same like PKG II. Activation of PKG I could inhibit the EGF-induced proliferation, invasion, and metastasis of EOC. Next, we examined how PKG I impact on the tyrosine phosphorylation of EGFR and its downstream pathways. The MEK/ERK pathway is a major signaling pathway activated by EGFR signaling $[23,35]$. The EGFR/MEK/ERK pathway has been reported to be involved in tumor progression in a variety of cancers $[36,37]$. Here, our results showed that the activated PKG I decreased EGF-induced phosphorylation of EGFR (Y1068), c-Raf, MEK1/2, and ERK1/2 involved in the MEK/ERK pathway. Furthermore, translocation of $\mathrm{p}$-ERK1/2 into the nucleus was decreased dramatically by the activated PKG I. Such effects were also reversed by the Rp-8-Br-cGMPS treatment. To our knowledge, we first identified the role of PKG I in inhibiting EGF-induced EOC progression. It has been reported that the activation of PKG I $\beta$ is sufficient to inhibit cell growth and migration and induce apoptosis in human colon cancer cells. These effects are associated with the inhibition of the transcription of cyclin D1 and an increase in the expression of $\mathrm{p}^{2}{ }^{\mathrm{Cl}}$ [28]. Faranak F. et al. found that the activation of PKG by cGMP induced growth inhibition and apoptosis in MCF-7 and MDA-MB-468 breast cancer cell lines [38, 22].Traci R. T. et al. reported that SGC stimulators and PDE5 inhibitors with increased cGMP reduced cell viability and apoptosis in head and neck cancer [21]. These studies suggested that activated PKG I attenuated tumors growth. On the other hand, anti-apoptotic actions of sGC/cGMP pathway have been also reported in lung and ovarian cancers, suggesting that the outcome of PKG I activity depends on the cell-specific downstream effectors $[23,39]$. However, there was no report of activation PKG I on EGF-induced EGFR/ERK signaling pathway activation in EOC. Our study indicated that activated PKG I physically interacted with EGFR and induced its serine and threonine phosphorylation, leading its threonine 693 site phosphorylation, which thereby inhibited EGFR tyrosine phosphorylation and the EGFR/MEK/ERK signal pathway.

\section{Conclusions}

Now, EGFR-targeted agents generated conflict therapeutic effects clinically. Thus, exploring the underlying mechanisms of anti-EGFR therapies is required. Here, we demonstrated that the elevated activated PKG I by 8-Br-cGMP can interact with EGFR and disrupt its downstream MEK/ERK pathway related to cancer progression. The 8-Br-cGMP-PKG I-EGFR/MEK/ERK axis might serve as a novel a target for EOC 
treatment. Several drugs for treating non-malignant conditions act by increasing cGMP, which activates PKG approved by FDA [21]. These drugs might be worth trying to treat EOC in clinical trials.

\section{Abbreviations}

EGFR: epidermal growth factor receptor;EOC: epithelial ovarian cancer; Grb2: growth factor receptorbound protein 2; MAPK: mitogen-activated protein kinase; MEK: mitogen-activated or extracellular signalregulated protein kinase; MMP-9: matrix metalloprotein 9; Ki-67: nuclear related antigen Ki-67; PKG I: type I cGMP-dependent protein kinase; Sos1: Son of seven-less 1; VASP: Vasodilator-stimulated phosphoprotein; 8-Br-cGMP: 8-Bromoguanosine-3',5'-cyclic monophosphate.

\section{Declarations}

\section{Ethics approval and consent to participate}

The experimental protocol was established according to the ethicalguidelines of the Helsinki Declaration and was approved by the HumanEthics Committee of Xuzhou Medical University.

\section{Consent for publication}

All of the authors have agreed to publish this article in your journal if itshould be accepted.

\section{Availability of data and materials}

The dataset supporting the conclusions of this article is included within thearticle.

\section{Competing interests}

The authors declare that they have no competing interests.

\section{Funding}

This study was supported by the National Natural Science Foundation of China (grant no. 81802063, 81802086, 81801168, 81971817), the Natural Science Foundation of the Jiangsu Higher Education Institutions of China (grant no. 18KJB320026, BK20160228, BK20180995), the Specialized Research Fund for Senior Personnel Program (grant no. D2016017, D2017022, D2019028) and the Young Science and Technology Innovation Team (grant no. TD202005) of Xuzhou Medical University.

\section{Author contributions}

Ting Lan: conceptualization, methodology, writing/original draft preparation, supervision; Ying Li: conceptualization, methodology, writing-review \& editing; Yue Wang: methodology, writing-review \& editing; Zhongcheng Wang: methodology, writing-review \& editing; Chunyan Mu: methodology, writingreview \& editing; Aibin Tao: validation, writing-review \& editing; Jianli Gong: validation, writing-review \& 
editing; Yuan Zhou: methodology, writing-review \& editing; Hao Xu: conceptualization; Shibao Li: conceptualization; Bing Gu: resources; Ping Ma: conceptualization, methodology, writing-review \& editing, supervision; Lan Luo: conceptualization, methodology, writing/original draft preparation, supervision.

\section{Acknowledgements}

The experiments in this article were partially completed in Public Experimental Research Center of Xuzhou Medical University, and thanks the teachersfor their support and help during the experiments. We also thank the Xuzhou MS diagnostic Co. Ltdfor their support during the Mass spectrometry experiments.

\section{References}

1. Bray F, Ferlay J, Soerjomataram I, Siegel RL, Torre LA, Jemal A. Global cancer statistics 2018: GLOBOCAN estimates of incidence and mortality worldwide for 36 cancers in 185 countries. CA Cancer J Clin. 2018; 68: 394-424.

2. Torre LA, Trabert B, DeSantis CE, Miller KD, Samimi G, Runowicz CD, et al. Ovarian cancer statistics, 2018. CA Cancer J Clin. 2018; 68: 284-96.

3. Reid BM, Permuth JB, Sellers TA. Epidemiology of ovarian cancer: a review. Cancer Biol Med. 2017; 14: 9-32.

4. Lheureux S, Gourley C, Vergote I, Oza AM. Epithelial ovarian cancer. The Lancet. 2019; 393: 1240-53.

5. Buys SS, Sandbach JF, Gammon A, Patel G, Kidd J, Brown KL, et al. A study of over 35,000 women with breast cancer tested with a 25-gene panel of hereditary cancer genes. Cancer. 2017; 123: 172130.

6. Daly MB, Pilarski R, Berry M, Buys SS, Farmer M, Friedman S, et al. NCCN Guidelines Insights: Genetic/Familial High-Risk Assessment: Breast and Ovarian, Version 2.2017. J Natl Compr Canc Netw. 2017; 15: 9-20.

7. Foulkes WD, Shuen AY. In brief: BRCA1 and BRCA2. J Pathol. 2013; 230: 347-9.

8. Veneris JT, Matulonis UA, Liu JF, Konstantinopoulos PA. Choosing wisely: Selecting PARP inhibitor combinations to promote anti-tumor immune responses beyond BRCA mutations. Gynecol Oncol. 2020; 156: 488-97.

9. Monk BJ, Minion LE, Coleman RL. Anti-angiogenic agents in ovarian cancer: past, present, and future. Ann Oncol. 2016; 27 Suppl 1: i33-i9.

10. Herbst RS. Review of epidermal growth factor receptor biology. Int J Radiat Oncol Biol Phys. 2004; 59: 21-6.

11. Gui T, Shen K. The epidermal growth factor receptor as a therapeutic target in epithelial ovarian cancer. Cancer Epidemiol. 2012; 36: 490-6.

12. Sheng Q, Liu J. The therapeutic potential of targeting the EGFR family in epithelial ovarian cancer. $\mathrm{Br}$ J Cancer. 2011; 104: 1241-5. 
13. Mehner C, Oberg AL, Goergen KM, Kalli KR, Maurer MJ, Nassar A, et al. EGFR as a prognostic biomarker and therapeutic target in ovarian cancer: evaluation of patient cohort and literature review. Genes Cancer. 2017; 8: 589-99.

14. Wang K, Li D, Sun L. High levels of EGFR expression in tumor stroma are associated with aggressive clinical features in epithelial ovarian cancer. Onco Targets Ther. 2016; 9: 377-86.

15. Siwak DR, Carey M, Hennessy BT, Nguyen CT, McGahren Murray MJ, Nolden L, et al. Targeting the epidermal growth factor receptor in epithelial ovarian cancer: current knowledge and future challenges. J Oncol. 2010; 2010: 568938.

16. Teplinsky E, Muggia F. EGFR and HER2: is there a role in ovarian cancer? Translational Cancer Research. 2015; 4: 107-17.

17. Skirnisdottir I, Akerud H, Seidal T. Clinical significance of growth factor receptor EGFR and angiogenesis regulator VEGFR2 in patients with ovarian cancer at FIGO stages I-II. Int J Oncol. 2018; 53: $1633-42$.

18. Lincoln TM, Dey N, Sellak H. Invited review: cGMP-dependent protein kinase signaling mechanisms in smooth muscle: from the regulation of tone to gene expression. J Appl Physiol (1985). 2001; 91: 1421-30.

19. Lohmann SM, Vaandrager AB, Smolenski A, Walter U, De Jonge HR. Distinct and specific functions of cGMP-dependent protein kinases. Trends Biochem Sci. 1997; 22: 307-12.

20. Piazza GA, Ward A, Chen X, Maxuitenko Y, Coley A, Aboelella NS, et al. PDE5 and PDE10 inhibition activates cGMP/PKG signaling to block Wnt/beta-catenin transcription, cancer cell growth, and tumor immunity. Drug Discov Today. 2020.

21. Tuttle TR, Mierzwa ML, Wells SI, Fox SR, Ben-Jonathan N. The cyclic GMP/protein kinase G pathway as a therapeutic target in head and neck squamous cell carcinoma. Cancer Letters. 2016; 370: 27985.

22. Fallahian F, Karami-Tehrani F, Salami S, Aghaei M. Cyclic GMP induced apoptosis via protein kinase $\mathrm{G}$ in oestrogen receptor-positive and -negative breast cancer cell lines. FEBS J. 2011; 278: 3360-9.

23. Leung EL, Wong JC, Johlfs MG, Tsang BK, Fiscus RR. Protein kinase G type lalpha activity in human ovarian cancer cells significantly contributes to enhanced Src activation and DNA synthesis/cell proliferation. Mol Cancer Res. 2010; 8: 578-91.

24. Leung EL, Wong JC, Johlfs MG, Tsang BK, Fiscus RR. Protein kinase G type lalpha activity in human ovarian cancer cells significantly contributes to enhanced Src activation and DNA synthesis/cell proliferation. Mol Cancer Res, 2010, 8: 578-91.

25. Mujoo K, Sharin VG, Martin E, Choi BK, Sloan C, Nikonoff LE, et al. Role of soluble guanylyl cyclasecyclic GMP signaling in tumor cell proliferation. Nitric Oxide-Biol Ch. 2010; 22: 43-50.

26. Bull Phelps SL, Schorge JO, Peyton MJ, Shigematsu H, Xiang LL, Miller DS, et al. Implications of EGFR inhibition in ovarian cancer cell proliferation. Gynecol Oncol. 2008; 109: 411-7.

27. Smolenski A, Burkhardt AM, Eigenthaler M, Butt E, Gambaryan S, Lohmann SM, et al. Functional analysis of cGMP-dependent protein kinases I and II as mediators of NO/cGMP effects. Naunyn 
Schmiedebergs Arch Pharmacol. 1998; 358: 134-9.

28. Browning DD. Protein kinase $\mathrm{G}$ as a therapeutic target for the treatment of metastatic colorectal cancer. Expert Opin Ther Targets. 2008; 12: 367-76.

29. Browning DD, Kwon IK, Wang R. cGMP-dependent protein kinases as potential targets for colon cancer prevention and treatment. Future Med Chem. 2010; 2: 65-80.

30. Deguchi A, Thompson WJ, Weinstein IB. Activation of protein kinase $\mathrm{G}$ is sufficient to induce apoptosis and inhibit cell migration in colon cancer cells. Cancer Res. 2004; 64: 3966-73.

31. Hou Y, Gupta N, Schoenlein P, Wong E, Martindale R, Ganapathy V, et al. An anti-tumor role for cGMPdependent protein kinase. Cancer Lett. 2006; 240: 60-8.

32. Wu Y, Cai Q, Li W, Cai Z, Liu Y, Li H, Pang J, Chen Y. Active PKG II inhibited the growth and migration of ovarian cancer cells through blocking Raf/MEK and PI3K/Akt signaling pathways. Biosci Rep. 2019; 39: 8.

33. Eccles SA. The epidermal growth factor receptor/Erb-B/HER family in normal and malignant breast biology. Int J Dev Biol. 2011; 55: 685-96.

34. Wong AST, Kim SO, Leung PCK, Auersperg N, Pelech SL. Profiling of protein kinases in the neoplastic transformation of human ovarian surface epithelium. Gynecologic Oncology. 2001; 82: 305-11.

35. Martinelli E, Morgillo F, Troiani T, Ciardiello F. Cancer resistance to therapies against the EGFR-RASRAF pathway: The role of MEK. Cancer Treat Rev. 2017; 53: 61-9.

36. Takasawa K, Takasawa A, Osanai M, Aoyama T, Ono Y, Kono T, et al. Claudin-18 coupled with EGFR/ERK signaling contributes to the malignant potentials of bile duct cancer. Cancer Lett. 2017; 403: 66-73.

37. Zhang X, Gao D, Fang K, Guo Z, Li L. Med19 is targeted by miR-101-3p/miR-422a and promotes breast cancer progression by regulating the EGFR/MEK/ERK signaling pathway. Cancer Lett. 2019; 444: 105-15.

38. Fallahian F, Karami-Tehrani F, Salami S. Induction of apoptosis by type lbeta protein kinase $G$ in the human breast cancer cell lines MCF-7 and MDA-MB-468. Cell Biochem Funct. 2012; 30: 183-90.

39. Lodygin $D$, Menssen A, Hermeking H. Induction of the Cdk inhibitor p21 by LY83583 inhibits tumor cell proliferation in a p53-independent manner. J Clin Invest. 2002; 110: 1717-27.

\section{Figures}


A

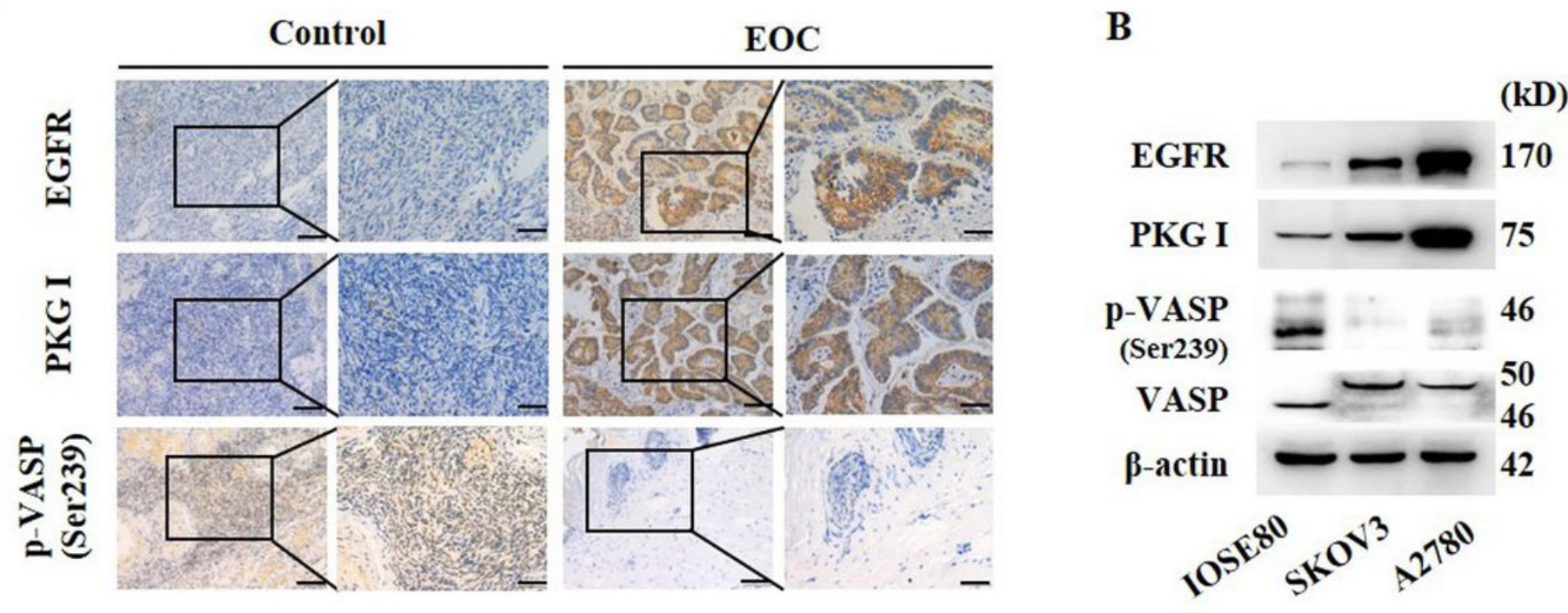

C
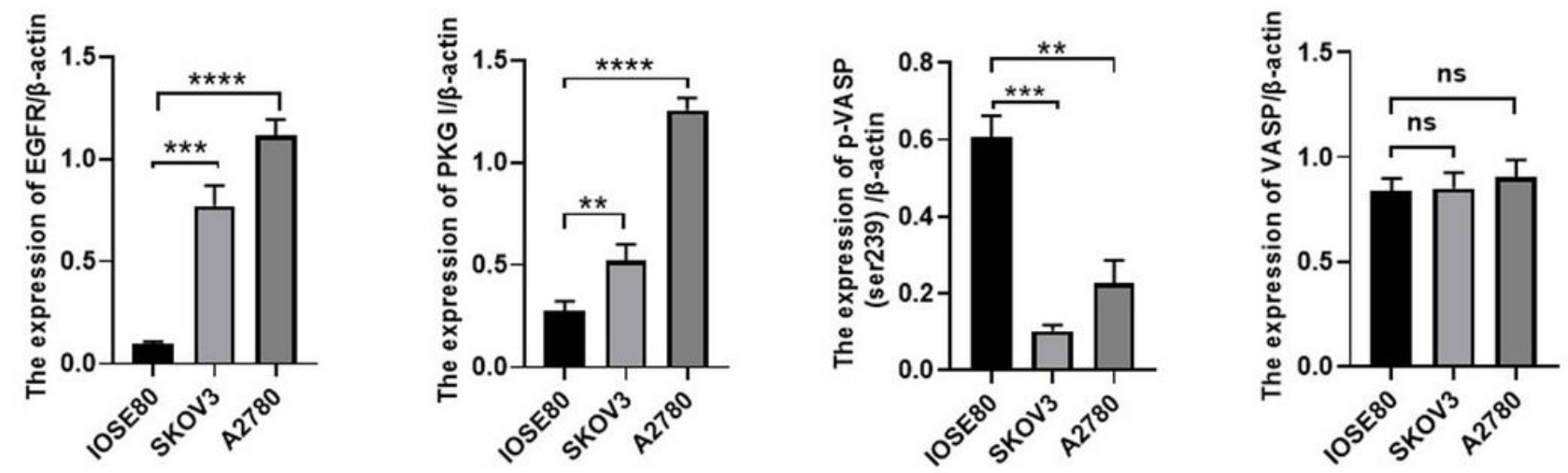

Figure 1

The phosphorylation levelsof VASP (p-VASP) are significantly decreased in epithelial ovarian cancer (EOC) patient tissue and cell lines.(A) Represent immunohistochemistry images on the EGFR, PKG I, and p-VASP (Ser239) expressions in the adjacent normal and tumor tissues of EOC patient. Scale bar: $100 \mu \mathrm{m}$ (left), $50 \mu \mathrm{m}$ (right). (B, C) Western blot analysis identified that the expressions of EGFR, PKG I, and VASP in EOC cells (SKOV3 and A2780) was higher than that of normal ovarian epithelial cells (IOSE80). But the activity of VASP estimated by p-VASP (Ser239) was lower in SKOV3 and A2780 cells than that of IOSE80

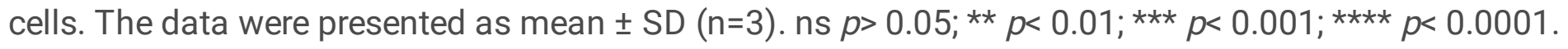


A
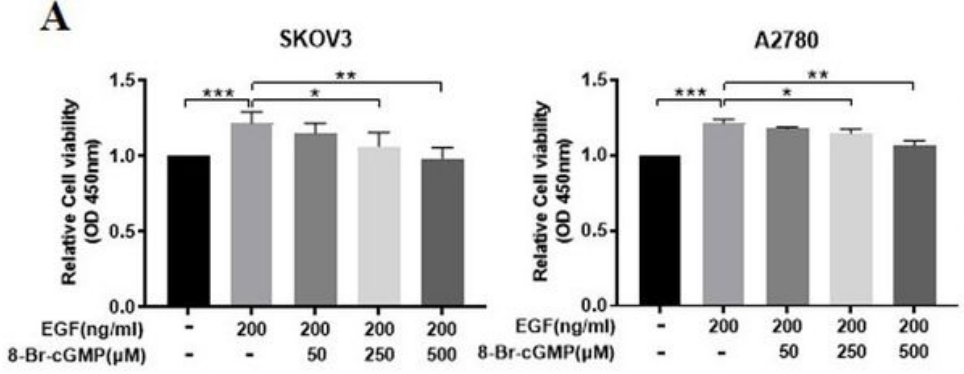

C

A2780

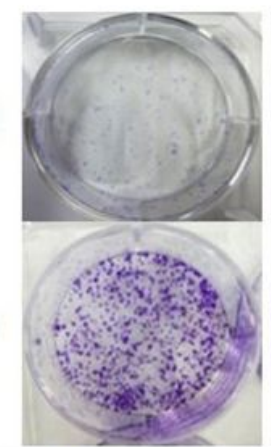

EGF(ng/ml)

8-Br-cGMP( $(\mu \mathrm{M})$

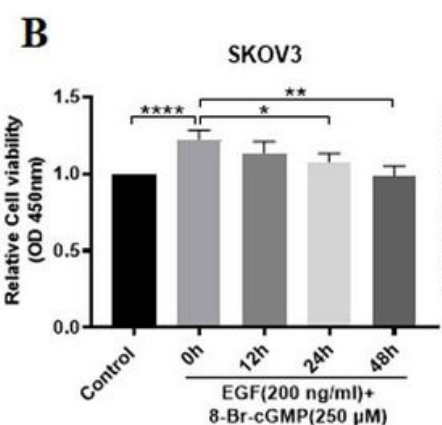

D

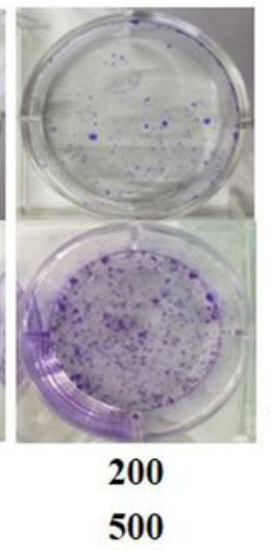

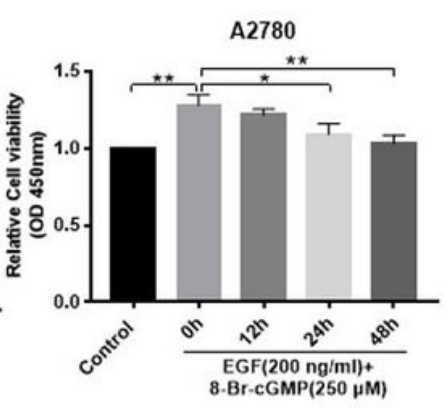

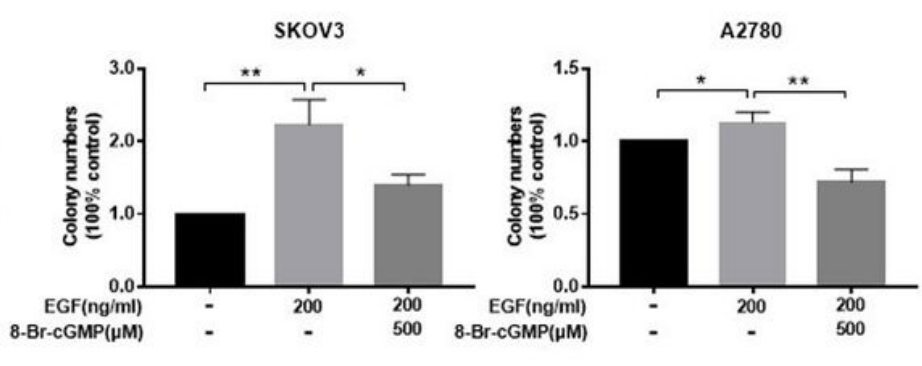

Figure 2

Activation of PKG I attenuated EGF-induced EOC cell proliferation in vitro. (A) The 24h-EGF treatment (200 $\mathrm{ng} / \mathrm{ml}$ ) significantly increased the cell viability of SKOV3 and A2780 cells using the CCK-8 assay. And, EGF-induced EOC cell proliferation was attenuated by the 8 -Br-cGMP supplement dose-dependently $(0,50$, 250, $500 \mu \mathrm{M})$. (B) The supplement of EGF (200 ng/ml) and 8-Br-cGMP $(250 \mu \mathrm{M})$ significantly decreased cell viability of SKOV3 and A2780 cells at 24 and 48h compared with that of Oh culture. (C) Represent colony assay images of SKOV3 and A2780 cells with indicated EGF (200 ng/ml) and 8-Br-cGMP (500 $\mu \mathrm{M}$ ) treatment. (D) Quantitative data on the colony number of SKOV3 and A2780 cells with indicated EGF $(200 \mathrm{ng} / \mathrm{ml})$ and 8-Br-cGMP $(500 \mu \mathrm{M})$ treatment. The data were presented as mean $\pm \mathrm{SD}(\mathrm{n}=3)$. ${ }^{\star} p<0.05$;

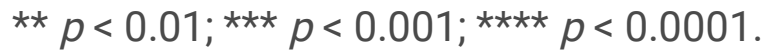


A
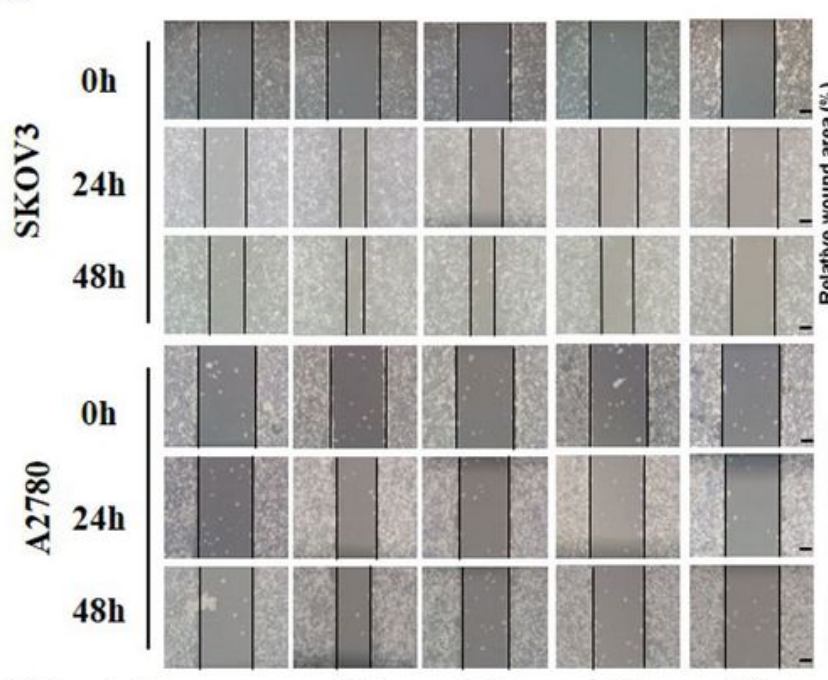

$\begin{array}{cccccc}\operatorname{EGF}(\mathrm{ng} / \mathrm{ml}) & - & 200 & 200 & 200 & 200 \\ & - & - & 50 & 250 & 500\end{array}$

C

SKOV3
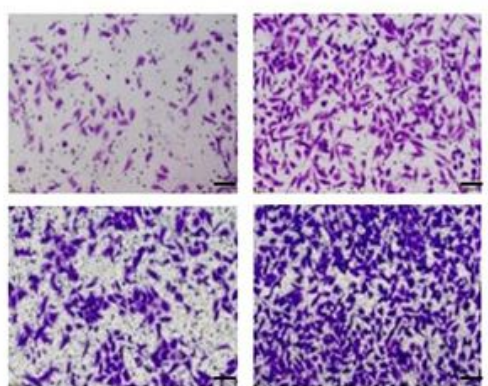

$\mathbf{A 2 7 8 0}$

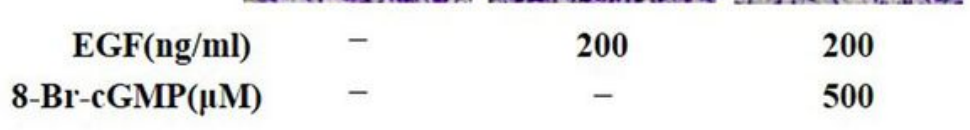

E

$\mathbf{A 2 7 8 0}$

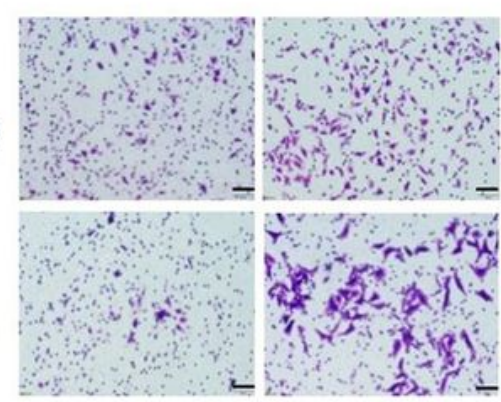

EGF(ng/ml)

8-Br-cGMP( $\mu M)$
200

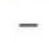

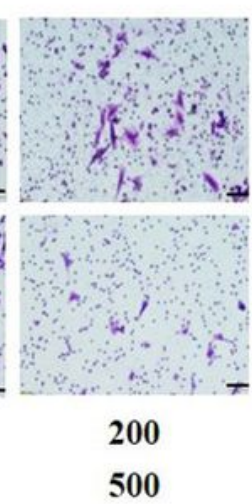

B

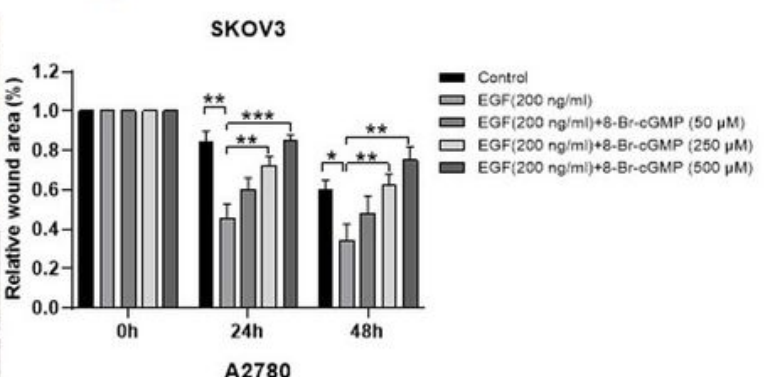

A2780
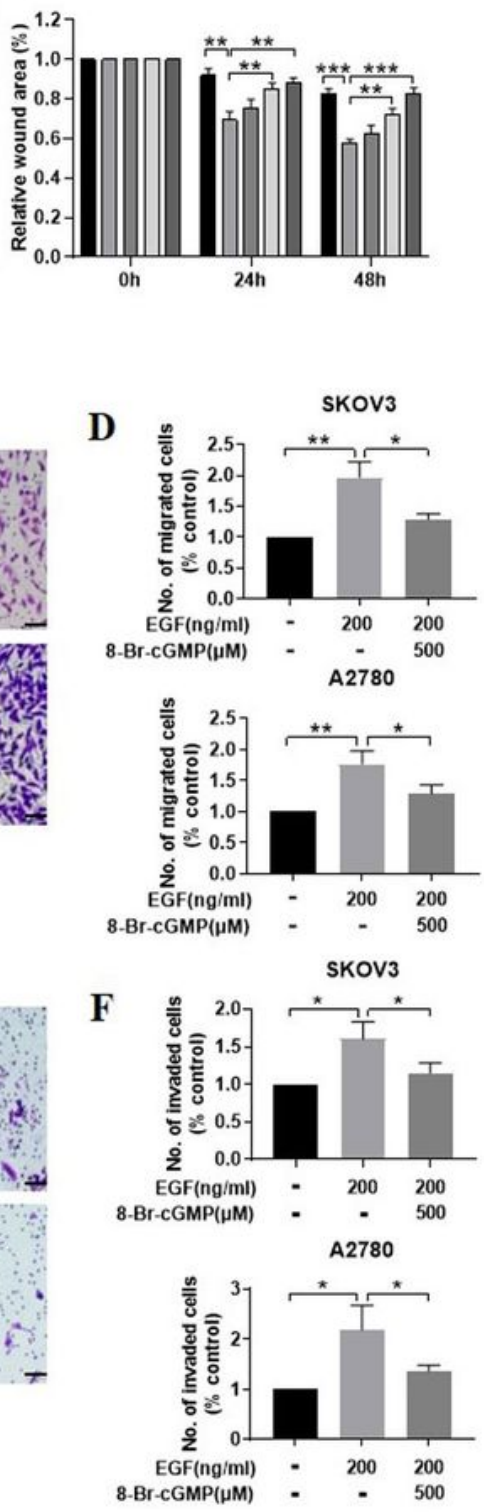

\section{Figure 3}

Activation of PKG I attenuated EGF-induced EOC cell migration and invasion in vitro. (A) Represent wound healing assay images of SKOV3 and A2780 cells co-cultured with indicated EGF and 8-Br-cGMP at 0, 24, and $48 \mathrm{hrs}$. Scale bar, $100 \mu \mathrm{m}$. (B) Relative quantitative data on the wound area of SKOV3 and A2780 cells with indicated EGF and 8-Br-cGMP. Trans-well assay was used to detect the effect of PKG I activation on the migration (C) and invasion (E) ability of SKOV3 and A2780 cells. Scale bar, $50 \mu \mathrm{m}$. 
Representative images were shown, respectively. (D, F) Quantitative data on the migrated and invaded SKOV3 and A2780 cells of Trans-well assay. The data were presented as mean $\pm \mathrm{SD}(\mathrm{n}=3) .{ }^{*} p<0.05 ; * \star p$ $<0.01 ; * \star *$ p 0.001 .

A

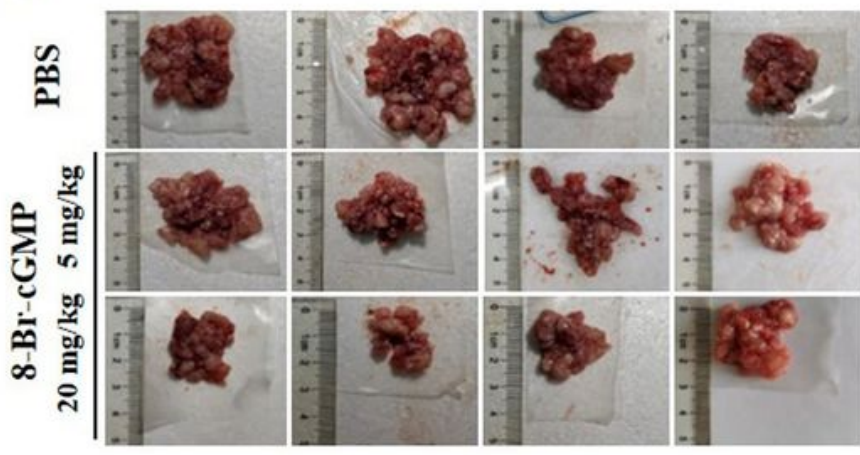

C

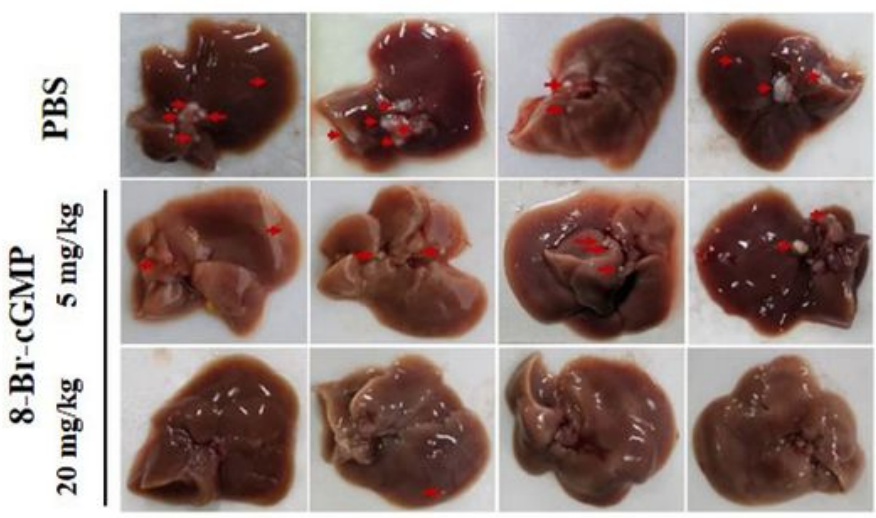

B

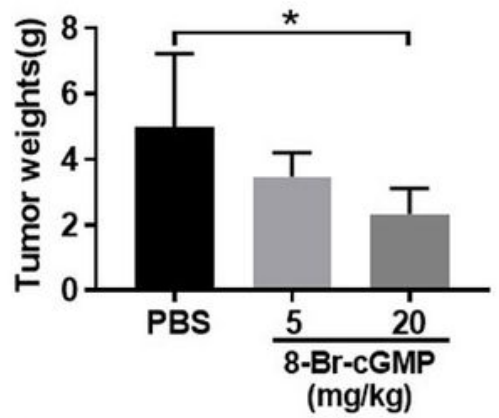

D

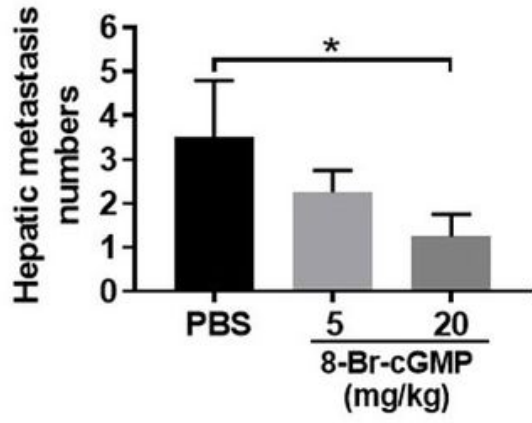

$\mathbf{E}$

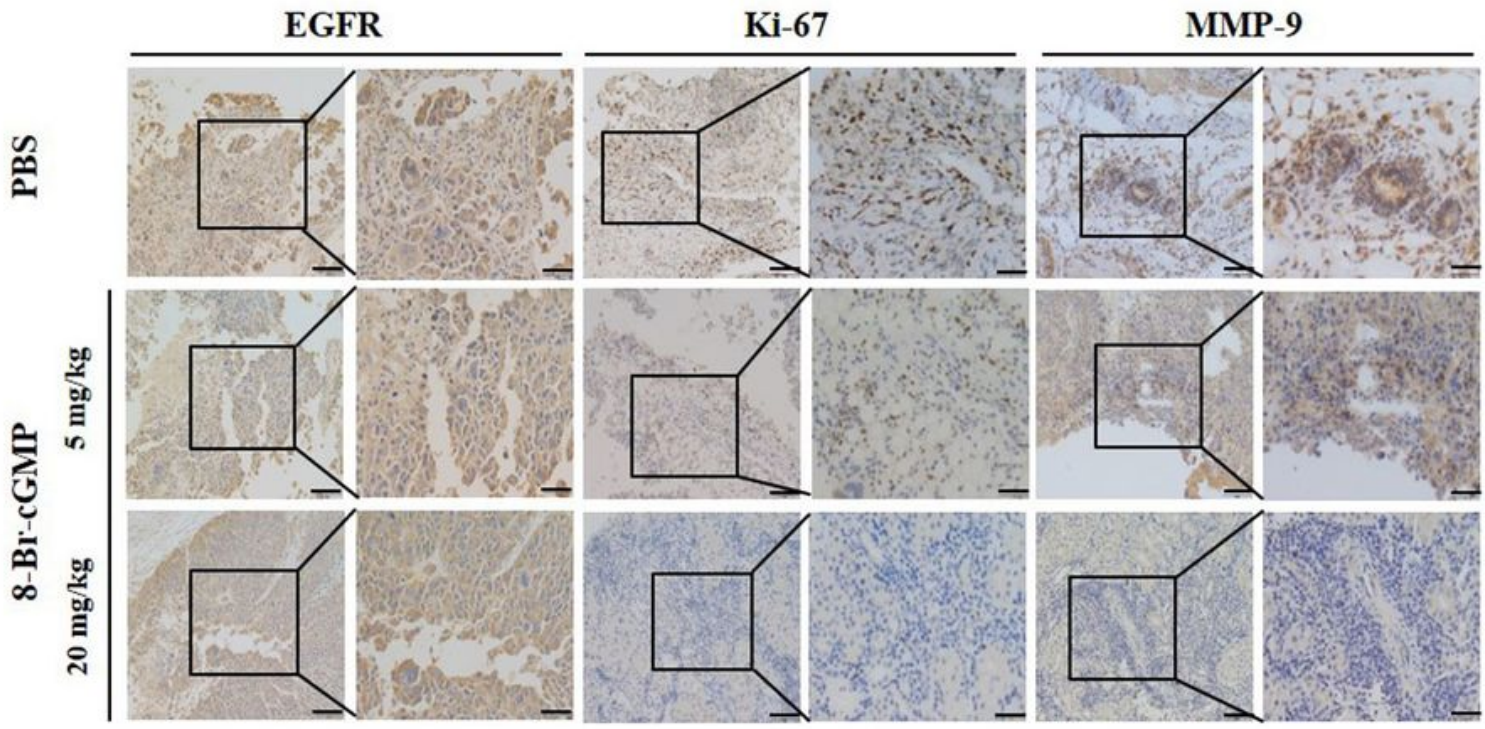

Figure 4 
Activation of PKG I suppressed tumorigenesis and metastasis in vivo using an EOC xenograft model. (A) Images of generated tumors in nude mice injected with A2780 cells and the administration of PBS or 8Br-cGMP ( 5 or $20 \mathrm{mg} / \mathrm{kg}$ ). (B) Quantitative data on the tumor weight of nude mice administrated with PBS or 8-Br-cGMP (5 or $20 \mathrm{mg} / \mathrm{kg}$ ). (C) Images of hepatic metastasis (indicated by the red arrow) in nude mice injected with A2780 cells and the administration of PBS or $8-B r-c G M P$ ( 5 or $20 \mathrm{mg} / \mathrm{kg}$ ). (D) Quantitative data on the number of hepatic metastasis in nude mice administrated with PBS or 8-BrcGMP (5 or $20 \mathrm{mg} / \mathrm{kg}$ ). (E) The expressions of EGFR, Ki-67, and MMP-9 in tumor tissues of nude mice. Scale bar: $100 \mu \mathrm{m}$ (left), $50 \mu \mathrm{m}$ (right). The results were presented as mean $\pm \mathrm{SD}(\mathrm{n}=3) .{ }^{\star} p<0.05$. 
A
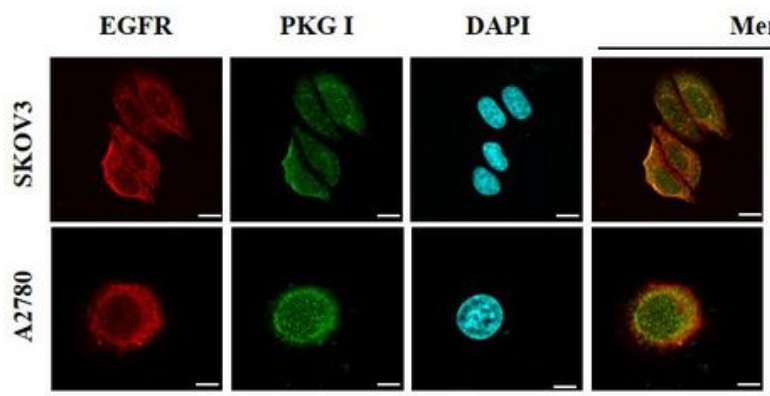

Merge

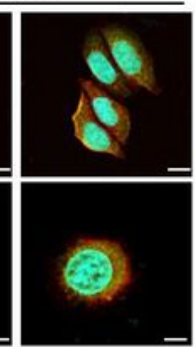

B
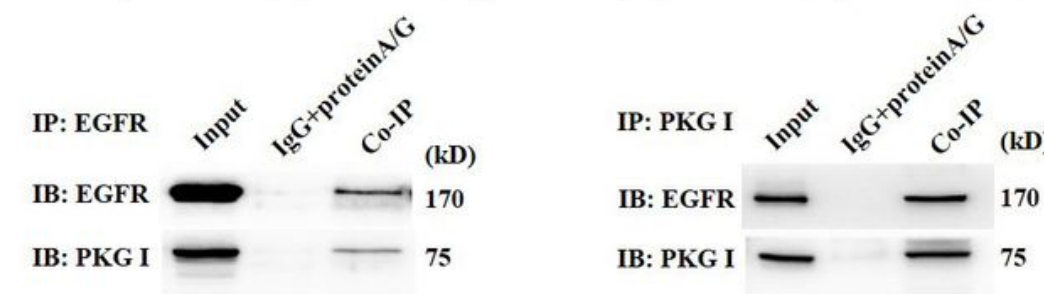

C

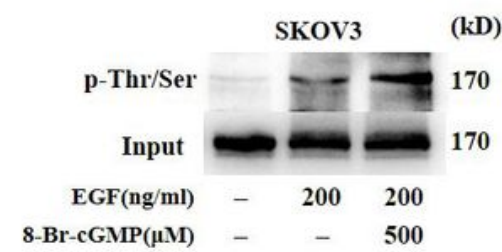

A2780

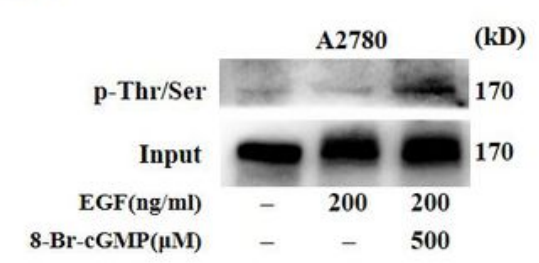

D

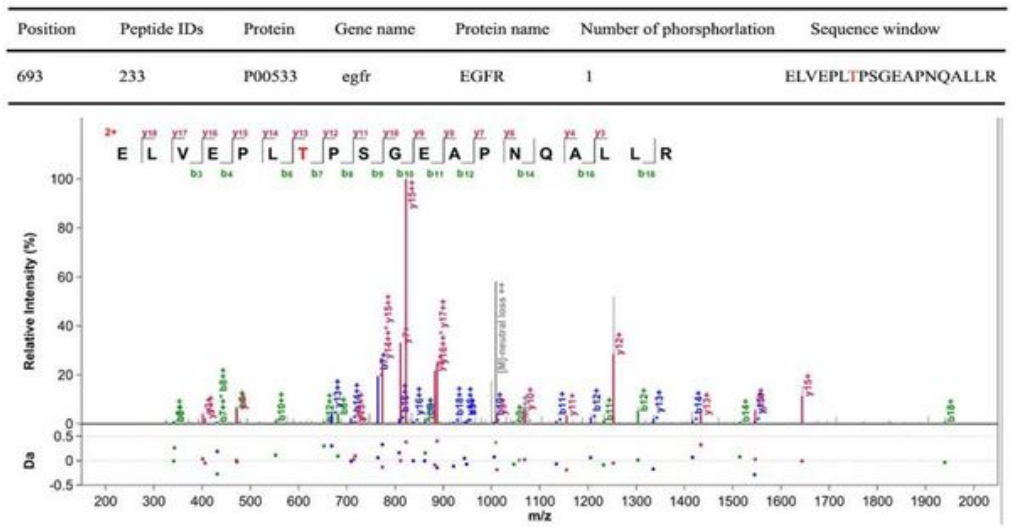

$\mathbf{E}$
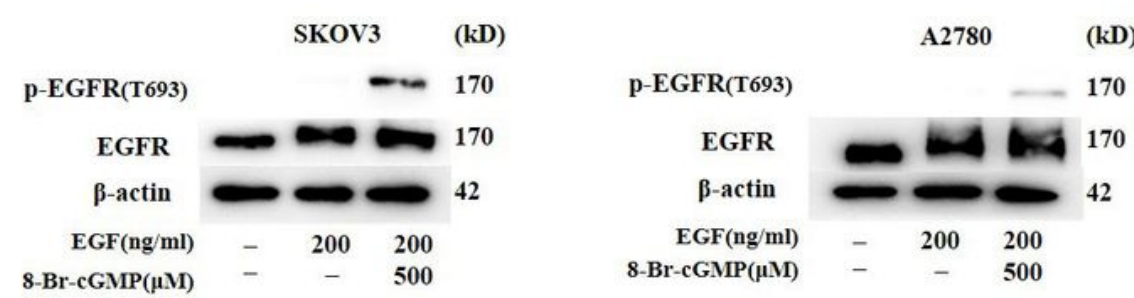

\section{Figure 5}

Activated PKG I bound with EGFR leading its serine and threonine phosphorylation. (A) Confocal laser scanning microscopy images on the expressions of EGFR and PKGI in SKOV3 and A2780 cells. Scale bar, $5 \mu \mathrm{m}$ (B) Co-IP assay revealed that PKG I bounded with EGFR in SKOV3 and A2780 cells. (C) Immunoprecipitation assay showed that activated PKG I caused serine and threonine phosphorylation of EGFR in SKOV3 and A2780 cells. (D) Mass spectrometry analysis identified that activated PKG I caused 
threonine 693 phosphorylation of EGFR. (E) Western blot analysis showed that activated PKG I caused phosphorylation of EGFR threonine 693 site in SKOV3 and A2780 cells.
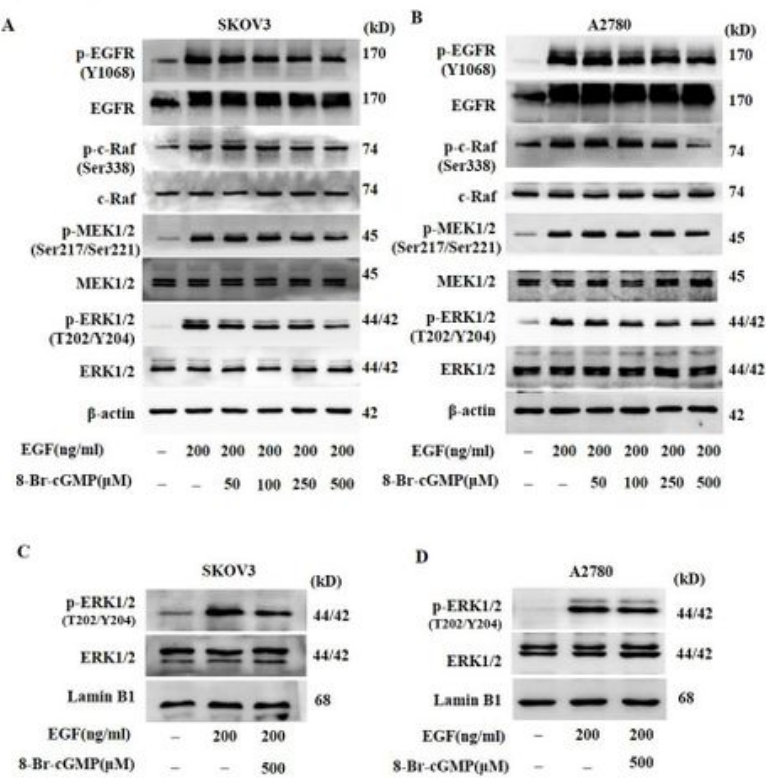

E

SKov3

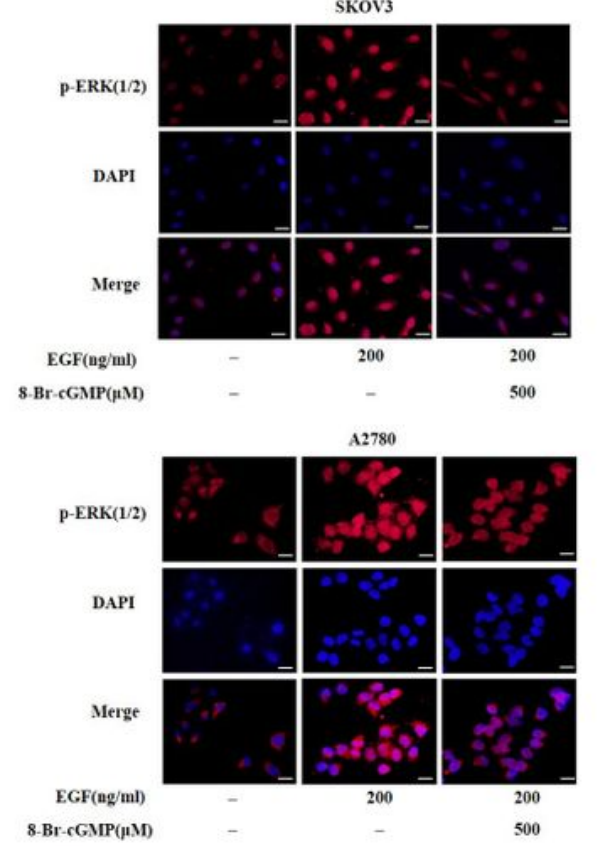

G

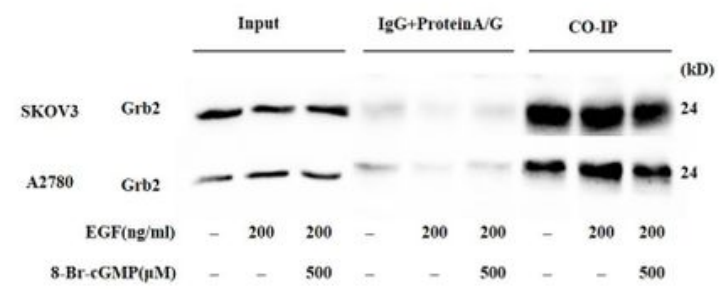

Figure 6

Activation of PKG I inhibited EGF-induced EGFR/MAPK/ERK pathway. (A, B) The activation of PKG I inhibited the phosphorylation levels of EGFR, c-Raf, MEK1/2, and ERK1/2 in SKOV3 and A2780 cells. 
Western blot (C, D) and immunofluorescence imaging (E, F) revealed that the 8-Br-cGMP $(500 \mu \mathrm{M})$ supplement declined the expression of nuclear phosphorylated ERK1/2 in SKOV3 and A2780 cells. Represent images were shown, respectively. Scale bar, $50 \mu \mathrm{m}$. (G) The Co-IP assay revealed that the 8-BrcGMP-induced EGFR/MAPK/ERK pathway blockade via hampering the EGF-induced EGFR-Grb2-SOS1 binding.

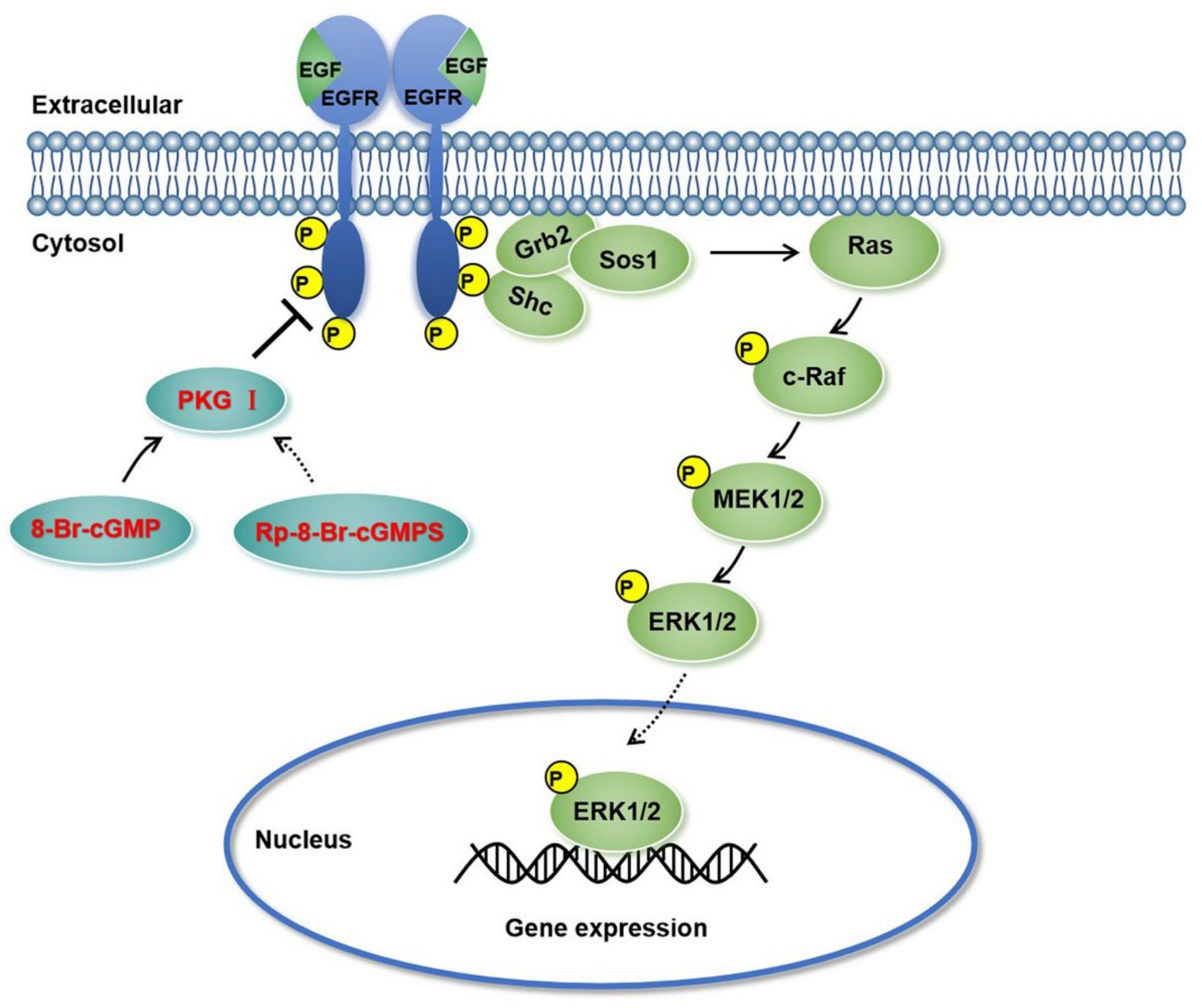

Figure 7

Schematic model of the activated PKG I attenuates EGF-induced EGFR/MAPK/ERK signaling in ovarian cancer. By binding to EGFR, the activated PKG I inhibits the expression of the EGFR/MAPK/ERK pathway and thereby decreases the expression of nuclear phosphorylated ERK $1 / 2$, ultimately leads to suppressed cell growth and metastasis in human EOC.

\section{Supplementary Files}


This is a list of supplementary files associated with this preprint. Click to download.

- Supplementfigurelegends.docx 